\title{
Context and Culture via Cohesive Devices in Higher Education Students' and Professional Writers' Opinion Articles
}

\author{
Emad A. S. Abu-Ayyash \\ emad.ayyash@buid.ac.ae \\ Faculty of Education, \\ British University in Dubai, United Arab Emirates
}

\begin{abstract}
The literature on cohesive devices is marked with evident dearth in studies that consider the context-text ties. The current paper attempts to fill this gap, and, therefore, combat an idealised 'villain' in research, which is confining textual analysis to in-text relations. The study propounds the idea of expanding the analysis to include ties between the written text and the surrounding context and culture. The specific purpose is to explore the use and function of the cohesive devices which link the text to the context (exophora) and the ones that relate the text to the culture (homophora). The methodology involved explaining the cohesive devices to a postgraduate TESOL class of eight students (non-native speakers of English) in one of the universities in the UAE. After that, the students were asked to work in pairs and produce four opinion articles about a recent newspaper topic of their choice. They selected the United Kingdom Independent Party (UKIP) leader's call to ban the burqa in the UK. In addition, two articles from the Independent and the Guardian on the same topic were also discussed. Comparative analysis was conducted on the six articles vis-à-vis the use and functions of cohesive devices. The analysis involved four categories: person deixis, spatial deixis, temporal deixis, and the definite article. The findings showed that exophoric and homopohric cohesive devices were employed abundantly, with exophora occurring in more instances. The study also revealed the relevant functions that have evident implications about assumptive and supportive roles of cohesive devices.
\end{abstract}

Keywords: exophoric reference; homophoric reference; cohesive devices; opinion articles; context and culture

\section{INTRODUCTION}

Halliday and Hasan (1976) designed a comprehensive model of textual analysis that, for the first time then, investigated the inter-sentential ties in texts, a model that stood at extreme contrast with the then-prevailing zeitgeist that opted for limiting the linguistic analysis to the sentence level. The 1976 model, which has loomed large in recent years in discourse analysis research (Abu-Ayyash, 2017; Awwad, 2017; Liu \& Braine, 2005; Struthers, Lapadat \& MacMillan, 2013), addressed the ties that existed between various stretches of texts, and classified the linguistic tools used to serve that purpose into two major categories: grammatical cohesive devices and lexical cohesive devices. The former set includes such textual relations as reference, substitution, ellipsis and conjunctions, while the latter encompasses ties like repetition, collocation, hyponymy, meronymy and synonymy - These devices are explained later within the conceptual framework. The choice of cohesive devices to examine textual ties is appropriate on a number of counts. Primary among those is that cohesive devices maintain text unity and can be considered an index of whether a series of sentences can or cannot be a text (Halliday \& Hasan, 1976). In fact, cohesive devices have been perceived as the sole instrument for non-structural textual analysis (Halliday \& Hasan, 1976), which means that for any linguistic analysis that seeks to go beyond the sentence level, cohesive devices are the sole 
instrument. More importantly, writers employ these tools to help readers understand their messages (Brown \& Yule, 1983), which is why cohesive devices were considered a significant index of coherence (Smith \& Frawley, 2009).

This last point about cohesive devices being tools of building text coherence has frequently been discussed in an ample body of textual analysis research (Crossley, Kyle \& McNamara, 2016; Struthers, Lapadat \& MacMillan, 2013). However, researchers who focused on the study of cohesive devices within the borders of the text have underscored the importance of understanding the relationships that exist between the linguistic items and the physical-world and cultural contexts. According to Abu-Ayyash (2017), due to the present research practice that focus on studies of cohesion mired in text-only-based analysis, there is a dearth of studies that link cohesive devices to context. As a matter of fact, such ties are significant to both the reader and the writer since both reading and writing are in essence social and cultural processes. Commenting on the acting of context on code, Widdowson (2004: p.8) states that "Unless it is activated by this contextual connection, the text is inert". Therefore, the problem addressed in the current study is a literature-based problem since the present literature on cohesive devices is marked with evident dearth apropos the text-culture and text-context dialogue. Such investigations are essential given that the three elements, text, culture and context, are inextricably linked (Widdowson, 2004).

In essence, this paper attempts to discuss the linguistic devices that link the text to its physical-world and cultural contexts, which are exophoric and homophoric devices (Paltridge, 2012; Halliday \& Matthiessen, 2014). To do so, the present study is set to serve the following aim: To explore the various functions of exophoric and homophoric reference in purposefully selected UK-based newspaper opinion articles and in EFL postgraduate students' opinion essays.

\section{CONCEPTUAL FRAMEWORK}

This section serves the purpose of delineating the main concepts allied to the foci of the present paper. Therefore, this part dwells upon cohesive devices on the one hand and the concepts of the physical-world and cultural contexts on the other. Although the notions of culture and context are hard to define, a minimum identification of their main components is handy for the goal of this paper, which aims to highlight the significance of two cohesive devices that link the code, or text, to the physical-world and cultural contexts. As for the cohesive devices introduced here, they incorporate those advanced by Halliday and Hasan (1976) and the offshoots of devices that were suggested by other scholars (e.g. Beaugrande and Dressler, 1981; Cutting, 2008; Gutwinski, 1976) ever since.

\section{COHESIVE DEVICES}

The earliest comprehensive account of cohesive devices was pinned in the theory of Systemic Functional Linguistics (SFL). The principles of this theory were revolutionary in that they called for extending textual analysis to include a unit that goes beyond the boundaries of the sentence, which is the text. SFL claimed that any linguistic analysis should consider the nonstructural ties (relationships that go beyond sentence boundaries) and should, therefore, focus on the entire text (Halliday \& Matthiessen, 2014). SFL theory explained that in order to consider the text as the unit of linguistic analysis, a clear instrument was needed, and the model of cohesive devices was introduced to fulfil the purpose of examining the inter-sentential ties. For the purpose of this paper, cohesive devices have been expounded in terms of two distinct categories: 1) in-text devices and 2) text-physical-world/cultural-context devices. The former group includes linguistic elements that can be decoded by referring to other parts within the 
text itself, while the latter group is compounded of textual elements that cannot be interpreted except by referring to worlds outside the text. Table 1 below includes examples on in-text ties based on Halliday and Hasan's (1976) model of cohesion.

TABLE 1. In-text cohesive devices

\begin{tabular}{|c|c|}
\hline Type of tie & Example \\
\hline Reference & $\begin{array}{l}\text { My two brothers achieved the highest grade in the math exam. They must have studied round the } \\
\text { clock. }\end{array}$ \\
\hline Substitution & I selected the white shirt. My cousin preferred the yellow one. \\
\hline \multirow[t]{2}{*}{ Ellipsis } & A: Are the kids doing their homework? \\
\hline & B: Yes, they are (doing their homework). \\
\hline Conjunctions & Peter did not catch the train. Therefore, he could not make it to the interview. \\
\hline Repetition & The tourists were lost in the desert for two days. The desert was really frightening at night. \\
\hline Collocation & My brother runs very fast. He only eats healthy food. \\
\hline Hyponymy & I could only buy three pieces of furniture yesterday. I bought a sofa, a bed and table. \\
\hline Synonymy & John lives in a large apartment. It is located in an enormous compound. \\
\hline Antonymy & I left London two days ago, and I've just reached my destination. \\
\hline Meronymy & My computer broke last night. There was something wrong with its battery. \\
\hline
\end{tabular}

It can be clearly seen from Table 1 that all the boldfaced linguistic items are linked to other items within the text and can be interpreted vis-à-vis these links. All the reference relationships that hold within the text itself were described in terms of endophora in the 1976 model. However, while the model identified two types of endophora, mainly anaphora (referring backward) and cataphora (referring forward), Cutting (2008) argued that in-text reference can also be described in terms of associative ties, where a noun phrase is linked to another noun phrase via a pool of knowledge. Cutting (2008) illustrates the associative reference tie using the statement "You Tube is a popular video sharing website..." and comments that the knowledge pool about websites would enable the reader to recognise that video sharing means online public viewing, rather than manually passing DVDs to friends.

Another category of cohesive devices, parallelism, was proposed by Gutwinski (1976) and strongly supported by Beaugrande and Dressler (1981). According to them, authors utilise repetition of a certain linguistic form or structure for emphatic purposes, and this type of repetition can be viewed as a cohesive device. Parallelism as a cohesive device was met with acceptance and was used in textual analysis in a number of papers (Abu-Ayyash 2017). While these cohesive devices have been exhausted in copious studies, there was a conspicuous disregard of the devices that link the code, or text, with the external environment, generally known as context. The second part of this conceptual framework comes to grips with the notion of context, and explains the cohesive devices that link to it and that will be employed in the instrument of the present paper.

\section{CONTEXT}

Generally, "The roles that context and world knowledge play in understanding are very important: potentially, any piece of information we know could be necessary to understand a particular sentence" (Harley, 2014: p. 15). Still, providing a strict definition of 'context' is not straightforward since the concept poses more challenges as to what exactly it means with reference to written texts. Considering spoken discourse, it was broadly agreed to call the world shared between the speaker and the listener 'situational context' (Halliday \& Hasan, 1976). The underlined linguistic items in (1) are an example of the notion of situational context.

(1) Give $\underline{\text { it }}$ to $\underline{\text { him}}$, please. 
In example (1), it is possible to decode it and him only if the context is shared, whether physically if the listener is in the same place and time as the speaker or digitally, if the listener can see the speaker via an online tool, such as Skype, for example. The notion of context in spoken discourse has drawn much less controversy than the concept of context in written discourse, however. Some scholars conceived of the context of written discourse as something very similar to that of spoken utterances and referred to it as the position of the word in a sentence, paragraph or a text, thus depicting context in terms of co-text, immediate context, or linguistic context (Scott \& Tribble, 2006). In this regard, context is considered as the outcome of placing words within longer stretches of language. This dimension of context as the surrounding text has salient links to in-text cohesive devices discussed in the previous subsection as it entails the presence of a relationship between linguistic items and their surrounding textual elements, but it has very little connection to ties that actually involve the physical-world/cultural-context connections. Quite understandably, the proposition of context as co-text has been rightly rejected as it implies that meaning is constrained only within the text, whereas discourse is better viewed as a phenomenon that cannot be understood independent from its broader social context (Teubert, 2010) and its cultural context (Philips \& Hardy, 2002).

This paper espouses Celce-Murcia and Olstain's (2000) definition of context as "all the factors and elements that are nonlinguistic and nontextual but which affect spoken or written communicative interaction" (p.11). Therefore, what came to be known as 'situational context' in spoken discourse will be termed as the physical-world context in this paper, which is concerned about written texts, and the linguistic items that can be decoded by referring to the physical-world context will be discussed in terms of exophoric reference (Halliday \& Hasan, 1976). Still, one more issue arises. The tools used in written discourse that link to the outer world, or context, do not always represent the physical world. In some instances, such linguistic items are very cultural. In (2), the interpretation of the prayer is culturally bound as it might refer to different things based on the culture it falls within.

\section{(2) The prayer will take place in five minutes.}

Such terms will be discussed under the umbrella of homophoric reference (Paltridge, 2012; Halliday \& Matthiessen, 2014). In essence, the concepts of physical-world context and culture are inextricably intertwined. However, certain distinctions can be made to avoid the overlap between the two when examining exophora and homophora, which is why the former will be looked at in terms of the physical milieu (place, time, people) surrounding the written text, and the latter in terms of the cultural setting, involving religion and traditions, for example. Such distinction between the physical-world context and the cultural context has grounding in recent studies that sought to examine cultural effects on cognition (e.g. Matsumoto, 2007; Dedios-Sanguineti, 2015).

Building on this distinction, a word on the role of the reader in decoding exophoric and homophoric reference merits consideration. Exophora involves a shared physical world between the writer and the reader, and it is this shared world that enables the reader to interpret the code with minimum effort. Homophora, on the other hand, calls for the reader's specific knowledge of the culture that underlies certain expressions in order to decode them, which makes homophora more reader-centred. What is common between these two devices is that they involve elements outside the text in order to decode textual items and that they imply a significant role of the reader in text interpretation, a role that was not given enough emphasis in previous studies, yet that was acknowledged to be significant (Johns, 1986). Without possessing the physical-world/cultural context awareness, the readers are hard put to make interpretations of exophorically and homophorically referring items employed in a written text. 
Given that, exophora and homophora also share the de facto status that they have been almost absent from research on cohesive devices, a practice that is evident in the literature.

\section{LITERATURE REVIEW}

This section, by examining the literature, seeks to clarify how the studies on cohesive devices have been frugal apropos addressing exophoric and homophoric devices. The majority of the studies that have investigated the use of cohesive devices so far have taken a beeline of addressing in-text ties, and their foci have generally accrued to the linguistic tools that serve the purpose of maintaining texture within texts. On a cautious note, in attempting to elucidate the gap in the literature on cohesion, the present study in no means undermines the studies that addressed in-text ties; on the contrary, the present paper attempts to add a small piece in the jigsaw, and is, therefore, an effort that builds on previous research.

One of the studies that may cast much light on the absence of exophoric and homophoric reference from a vast number of studies of cohesion was conducted by MohamedSayidina (2010). The paper, which investigated the transfer of L1 cohesive devices into L2 academic texts, provided the following definition for reference: "The use of pronouns (personal, demonstrative, comparative) to refer to an entity mentioned elsewhere in the discourse" (Mohamed-Sayidina, 2010: p.256). Limiting reference to relationships within the discourse may explain why exophora and homophora were not present in the paper's model of analysis, but it may also expound how these tools were, most probably inadvertently, stultified in research about cohesive devices.

A similar understanding of reference as a tie limited to in-text relations is manifested in a number of studies on cohesion (e.g. Bae, 2001; Yang \& Sun, 2012). Bae (2001) examines the correlation between the quality of children narrative written essays and the employment of cohesive devices. Among the grammatical cohesive devices (reference, substitution, ellipsis, conjunctions), only reference was found to hold a positive correlation with the writing quality. However, it is evident that exophoric reference and homophoric reference were not considered since Bae (2011) defined reference in terms of in-text decoding. In a study that analyses the correlation between cohesive tools and the quality of argumentative essays produced by university students, Yang and Sun (2012) define reference as "the set of grammatical resources which allow the writer/speaker to indicate whether something is being repeated from somewhere else in the text, or whether it has not yet appeared in the text" (p. 35). The last part of this definition calls for comment as it could be claimed that by saying "... whether it has not yet appeared in the text", Yang and Sun (2012) might be referring to exophoric relations. In fact, this part of the definition refers to cataphoric reference where the linguistic item can be interpreted by moving forward in the text, which means that the definition of reference provided by Yang and Sun (2012) is only inclusive of in-text relationships in terms of anaphora and cataphora.

Apart from the scope-limiting definitions found in a number of studies of cohesion, a ubiquitous investigation in many studies has been whether or not the employment of cohesive devices has an influence on the quality of writing. In such studies, it would be important to consider all cohesive devices, including exophoric and homophoric ties, which are tantamount to in-text ties because judging the quality of a text based on cohesive devices is a task that typically involves a reader's/rater's understanding of not only the text per se, but also the external links made to the physical context and the culture via linguistic tools. However, a salient observation is that dropping out exophora and homophora has so far been an ingrained practice in cohesive devices studies that investigated the relationship between the employment of these tools and the quality of writing. 
Very few studies addressed exophoric reference, none to my knowledge homophoric reference, from different perspectives and at various levels. One of the studies that analysed cohesive devices in a comprehensive way addressed the use of these linguistic tools in adult and children drama texts (Al-Pachachi \& Naser, 2016). The authors not only explain the cohesive devices that can link the various parts of the text together, but they also provide an account, though a brief one, on exophoric reference, thus referring to ties that exist between the text and its context. To elaborate more on the latter, Al-Pachachi and Naser provide the following example: "That must have cost a lot of money," (2017: p.34), explaining the pivotal role of context in the interpretation of 'That'. However, when the authors list the cohesive devices that occur in their sample of analysed drama texts, it becomes apparent that they have not considered exophoric reference and that they looked at the types of reference that hold within-textual links, such as anaphora and cataphora

Seemingly, Abdul Rahman (2013) acknowledges that one of the factors that should be taken into account when one writes is "the cultural and contextual frames around which the writer is situated" (p.2). Within the model of analysis that he uses in his paper, exophoric reference tops the list and is defined as reference to a nonlinguistic element. The following example is given in the paper: "(a teenager is listening to music) Father: Stop doing that. I want to read" (p.4). Nevertheless, the introduction of exophora in the model of cohesive devices in this paper does not go beyond that brief vignette, and this cohesive tool disappears from the main analysis of the paper afterwards.

Akin to this practice, Karadeniz (2017) acknowledges the role of the reader in text interpretation and explains that semantic ties can involve either two elements inside the text or one element inside the text and the other outside it. However, this emphasis, though core to the paper's investigation, did not get except a cursory coverage, and exophora and homophora were not part of the model used to analyse the cohesive devices.

Most recently, Awwad (2017) examined the role of exophoric and endophoric cohesion awareness on the encoding and decoding skills of first-year university non-native speaking (NNS) Lebanese university students. A significant portion of the conceptual framework of the paper is allocated to exophoric reference, which is elucidated in terms of referring to some extralinguistic situation concomitant to the utterance. The study maintains that the students' awareness of endophoric and exophoric references has a positive impact on their decoding and encoding skills. However, because the data are presented in quantitative form, little is revealed on how the participants were able to decode the functions of endophora and exophora in the given tests.

In a more telling study as far as exophora is concerned, Bahaziq (2016) maintains that identifying relationships between certain linguistic items and the outside world is an integral part of the analysis of cohesive devices. On exophoric reference, she provides the following example: "That is a wonderful idea" (p.113). To the paper's credit, exophoric reference is included in the data analysis with reference to the definite article: "The article the is mostly used as an exophoric reference to refer to the outside world shared between the writer and the reader" (Bahaziq, 2016: p.115). The paper then mentions five instances of this use. However, the study does not make any comments on the meaning or function of such usage and ends up listing the occurrences of exophora in the sample article used in the study.

To sum up, the dearth of investigations of exophoric and homophoric reference in the literature is evident. While this might be in large part due to the limited scope that views reference as a sole in-text tie, studies that acknowledged the existence of extra-textual ties mostly did not consider them in the data analysis. Exophoric reference, though, received what might at best amount to be a cursory coverage in some studies; yet, homophora was not considered for analysis in any of the previous studies. Therefore, the significance of this study stems from the fact that it fills a gap in the research conducted so far on cohesive devices. A 
word on the practical applications merits consideration at this juncture. In writing classes, it is important to draw the students' attention to the techniques they can employ to get their readers more involved in what they write. Mastering the use of cohesive devices that serve this function will equip the students with the necessary linguistic tools that they can utilise to create links between their texts and the outer world, including politics (Tan, 2019). Therefore, the practical application of such knowledge is two-fold: the ability to reflect culture and context via the use of cohesive devices in certain ways and winning more reader involvement with the texts.

\section{METHOD}

\section{INSTRUMENTATION}

Halliday and Hasan's (1976) model of cohesive devices and Hatch's (1992) categorisation of deictic markers have been conflated to build the instrument of the current paper. The reason why the categories advanced by Hatch (1992) were added to the well-known 1976 instrument is that they add more flesh to referential items that involve text-context/culture decoding. According to Hatch (1992: p.209), "Much of meaning can only be understood by looking at linguistic markers that have a pointing function in a given discourse context". Having said that, the instrument encompasses the devices that involve exophora and homophora, which are person deixis (personal pronouns), the definite article, spatial deictic markers, and temporal deictic markers. Figure 1 delineates the components of the framework used in the present paper.

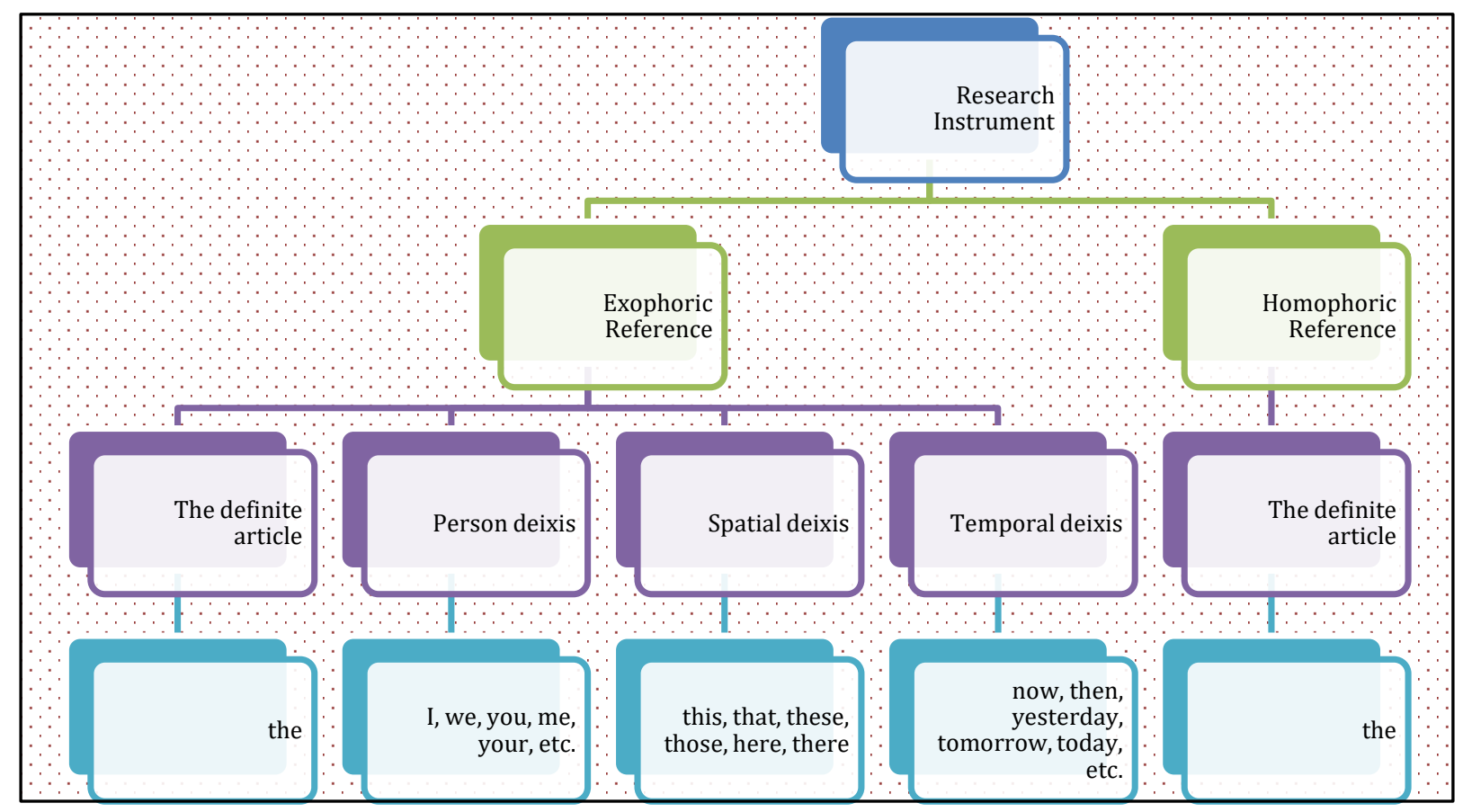

FIGURE 1. Framework of analysis

On a cautious note, all the linguistic items involved in the instrument of the current paper can also be endophoric, as they can refer to other linguistic items within the text. However, such in-text relations received only a cursory coverage, the reason of which is explicated in the findings section, as the present paper seeks to analyse the employment of textual items that are solely decodable in terms of non-textual factors. 


\section{PARTICIPANTS}

The participants in this paper were eight postgraduate TESOL students, all NNSs of English, who were registered in a discourse analysis module delivered in the academic year 2017 in the British University in Dubai, United Arab Emirates. The eight participants had similar language proficiency level as their academic IELTS scores ranged between 6.5 and 7 .

\section{PROCEDURE}

The cohesive devices were explained thoroughly and the eight students' knowledge of these tools was tested in two ways. The first way involved oral questions about the ties involved in examples presented on slides. The questions were primarily related to identifying the types of cohesive devices used in certain extracts. The second cohesive-devices knowledge test involved asking the participants to identify the linguistic items and the cohesive ties that they are involved in in a newspaper article.

Following the cohesive devices' explanation-and-assessment session, the students were asked to surf the online news and find a 'hot-potato' issue about which they would be interested in expressing their opinions. The eight participants agreed on Paul Nuttall's call for banning the face veil in the UK. The students were then divided into four groups of two and each pair was asked to write a 200+-word opinion article about Nuttall's call. The participants came from different cultural backgrounds as two of them were Emiratis, one Jordanian, one Syrian, one Egyptian, one Indian, one Iraqi and one Turkish. Table 2 is a manifestation of the distribution of the eight participants based on their nationalities, the corresponding essays and the number of words.

TABLE 2. Participants' nationalities and their productions

\begin{tabular}{ccc}
\hline Participants' nationalities & Essay & \# of words \\
\hline Turkey and Egypt & Ess-1 & 248 \\
India and Iraq & Ess-2 & 220 \\
Jordan and Syria & Ess-3 & 217 \\
UAE (2) & Ess-4 & 281 \\
\hline
\end{tabular}

The students were encouraged to deliberately use the cohesive devices they learned. The four resulting essays were then analysed with the focus on identifying the examples of homophoric and exophoric instances and in comparison to two purposefully selected opinion articles written about the same issue in the Independent and the Guardian. The two newspaper opinion articles were (Strickland, 2017) (Art-1), with 749 words, and (Grace, 2017) (Art-2), with 843 words.

\section{ANALYSIS AND CODING}

The comparative analysis, which sought to understand the extent and the ways in which homophora and exophora were used, is introduced based on the four categories of the instrument of analysis, namely person deixis, spatial deixis, temporal deixis, and the definite article. While the first three were discussed in terms of exophora, the last category was analysed vis-à-vis both exophora and homphora.

All the five categories were colour-coded in order to facilitate identifying and explaining all the occurrences of each category. The colour codes for each category and examples from the sample texts can be shown in Figure 2 (More examples of color-coded excerpts can be found in (Appendix A). 


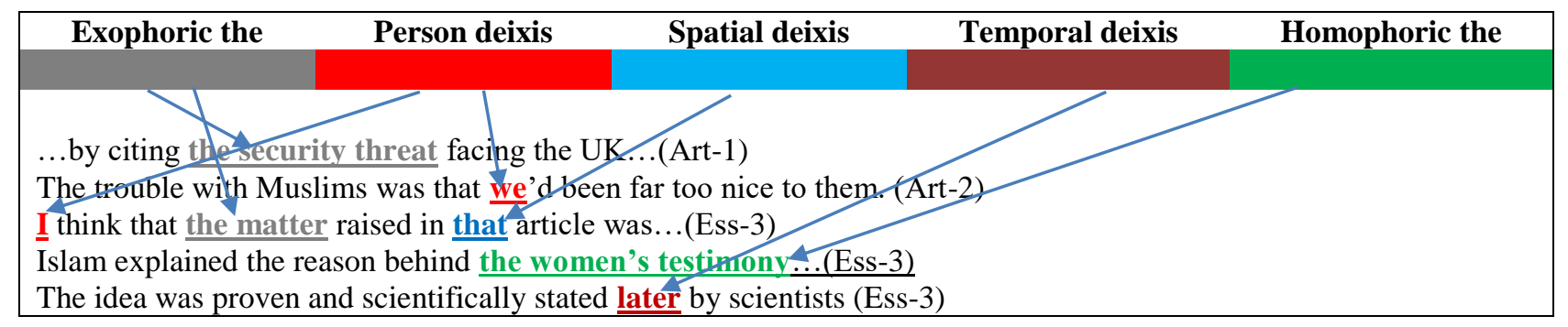

FIGURE 2. Colour coding illustration

\section{FINDINGS AND DISCUSSION}

This section attempts to elucidate the functions of exophoric and homophoric tools in the selected newspaper articles and the students' essays to meet the research aim. In order to make it easier to follow the analysis of the two newspaper articles the URLs for both is provided here; sample data from the articles and the four essays can be found in Appendix A.

Article 1: (http://www.independent.co.uk/voices/paul-nuttall-ukip-manifesto-burqa-ban-maleviolence-muslim-women-a7698771.html)

Article 2: (https://www.theguardian.com/politics/2017/apr/24/ukip-integration-policy-launchdescends-into-full-integrated-fiasco).

In terms of the number of occurrences of the various exophoric and homophoric devices employed across the six texts, Table 3 shows that there are 84 instances of those devices: 8 homophoric and 76 exophoric, which could be rightly anticipated due to the fact that the linguistic tools that can be used exophorically outnumber those that can be used in homophoric relationships as shown in the instrument described in the previous section.

TABLE 3. Occurrences of exophora and homophora in the sample texts

\begin{tabular}{|c|c|c|c|c|c|}
\hline Essay/Article & Exophoric the & Person deixis & Spatial deixis & Temporal deixis & Homophoric the \\
\hline Art-1 & 6 & 16 & Nil & 3 & 2 \\
\hline Art-2 & 10 & 3 & Nil & 7 & 2 \\
\hline Ess-1 & 3 & 10 & Nil & Nil & 1 \\
\hline Ess-2 & 1 & Nil & Nil & Nil & Nil \\
\hline Ess-3 & 2 & 4 & 1 & 1 & 2 \\
\hline Ess-4 & 4 & 4 & 1 & Nil & 1 \\
\hline
\end{tabular}

It could be argued at this point that previous research focused on endophoric reference because it occurs much more in various types of texts. In order to eliminate this line of thought, the total number of exophoric and homophoric reference items in the six texts was compared to the instances of endophoric (whether anaphoric or cataphoric) reference. As shown in Table 4 , the total number of endophoric items in the six texts was 141, compared to 84 of exophoric and homophoric items, which means that up to 4 in 10 referring items could be decoded by going outside the text.

TABLE 4. Exophora, homophora and endophora occurrences

\begin{tabular}{ccc}
\hline & Exophoric and Homophora & Endophora \\
\hline Art-1 & 28 & 31 \\
Art-2 & 22 & 58 \\
Ess-1 & 14 & 10 \\
Ess-2 & 1 & 23 \\
Ess-3 & 9 & 10 \\
Ess-4 & 10 & 9 \\
\hline
\end{tabular}


The remaining part of this section is divided into five sub--sections, with each one presenting and discussing the findings pertinent to the functions of 'exophoric-the', person deixis, spatial deixis, temporal deixis and 'homophoric-the' in the six texts.

\section{EXOPHORIC-THE}

'Exophoric-the' was used 26 times in all the six articles to serve two functions: one supportive and the other assumptive. Starting with Art-1, Strickland (2017) argues that Muslim women's burqa does not pose a bigger threat to security than white men. It can be clearly noticed that all the six 'exophoric-the' references support the article's overall argument in a substantial way. The first two instances of 'exophoric-the' are used to flag the contradictory positions of the UKIP leader with regard to the burqa ban, citing his 2013 quotation "What we wouldn't do is go down the line of enforcing a blanket ban", and then the change in his position justifying it with 'the security threat' facing the UK. In the third occurrence, the writer uses 'exophoricthe' to argue that Nuttall's calls for the burqa ban only stem from the agenda of his party, no more no less. While the first three occurrences of 'exophoric-the' reveal the contradictory and unreasonable pretext behind the burqa-ban call, the remaining occurrences systematically provide two examples of a similar policy that was really implemented in France, but failed to stop security threats. These two 'exophoric-the' examples involved referring to 1) the devastating Bastille Day Promenade des Anglais truck attack, and 2) the Champs Elysees shooting. The last usage of exophora builds on these two indicating that 'the Westminster Bridge terror attack' in the UK would not have been stopped had the policy Nuttall was calling for been in place. Supporting the overall argument of the article using 'exophoric-the' can be clearly seen in Ess-1, where two of the three occurrences of this device indicate that the national security and the dangers facing Britain cannot be related to 'a single piece of cloth', or burqa.

A similar attempt to support the argument using 'exophoric-the' was noticed in Ess-2, which employed one such tool via the expression "the anti-Islamic political environment". Put within its immediate context, the exophoric expression can be taken as a reflection of the article's overall argument, which discusses Nuttall's call in terms of 'targeting Muslims', failing to call for a similar policy against 'the Jewish community' and the more direct accusation implied in the concluding statement 'It is apparent that makers of those policies of Nuttall's party are anti-Islamic'.

In Art-2, in which Grace (2017) puts the burqa ban call within the immediate context of elections and the competition between parties, 'exophoric-the' was used ten times to reflect the contextual background of the article and to support the author's argument about the heated electoral competition. Table 5 identifies the number of occurrences of 'exophoric-the' and the expressions these occurrences were involved in.

TABLE 5: Exophoric occurrences in Art-2

\begin{tabular}{cl}
\hline Number of occurrences & Expression as used in the article \\
\hline 2 & The UKIP Leader \\
1 & the central London hotel \\
1 & the election \\
3 & the national executive committee/ NEC \\
1 & the story \\
1 & the other mainstream parties \\
\end{tabular}

It is worth pointing out that all 'exophoric-the' occurrences in the article are there to maintain the correspondence between the article's argument, manifested in the text, and the contextual background, represented by people (the UKIP leader), places (the Central London 
hotel), events (the election), and the opposing parties (the Tories). It has become clear by now that involving the readers in decoding certain expressions by making outside-text links is purposefully used to support the argument of the author.

While the illustrated examples of 'exophoric-the' are a manifestation of the supportive function of this cohesive tool, there are instances where 'exophoric-the' has played an assumptive function as it reflected the writers' inclination to assume that the readers/audience know what they mean without further explanation. The assumptive purpose of 'exophoric-the' was noticed in Ess-3 and Ess-4. In the former, there are two 'exophoric-the' usages, in both of which the writers' assumptions are that the readers know what the references are. The two students who wrote Ess-3 used 'exophoric-the' twice. They start their argument with "I think that the matter raised in that article...". The 'exophoric-the' expression in this excerpt clearly assumes that the readers know what the matter is. The other occurrence, which is 'the writer', also assumes that the author of the Guardian's article is known to the readers. Assumptive 'exophoric-the' is also present in three out of four occurrences in Ess-4: the given problem, the article, the arguments. In these three occurrences, the writers assume that the readers know what or who the references of these expressions are, which is why no textual clues were provided to enable the readers to decode the three expressions based on the text alone.

\section{PERSON DEIXIS}

Person deixis was utilised in all the sample texts except Ess-2 to serve a variety of functions. The most prominent of those was readers' involvement in the argument through arousing their emotions and via attempting to persuade them using logical argumentation. This function of person deixis is salient in Art-1, which uses 'you' and 'we', or one of their forms, such as 'our', in 15 out of 16 examples to engage the readers in logical arguments or emotional involvement. Consider this statement from the article: "If you pick a newspaper today you will see examples of white men harming women, children, minority ethnic groups and each other". Apparently, this is a reader-involvement call to engage in an objective investigation that will eventually support the author's argument. In the same article, emotional, reader-involvement is also present, with a statement like "How dare we then tar all with the same brush?" Similar usages are manifested in Ess-1, where reader involvement, particularly women here, is part of a logical argumentation in statements like "Placing a cloth around your neck is considered as a peaceful act while placing it on your nose and mouth is a terroristic one", and is part of emotional arousing with a statement like "I am sorry you have lost it" and "We should be humanistic and peaceful".

Another function of exophoric person deixis was emphasising the 'self-versus-others' beliefs, a function that is patent in Ess-3 and Ess-4. This use of exophora is consistent with both essays' tendency to discuss Nuttall's call in terms of a broader conflict between Islam and anti-Islamic parties. Taken together, out of the 8 examples of exophoric person deictic expressions, 5 employed ' $\mathrm{I}$ ' and the remaining three 'they' and 'their'. This function of exophora can be taken as one major building block of the argument presented in both essays.

\section{SPATIAL DEIXIS}

This form of exophoric reference was the least used across the six articles and essays, with only 2 occurrences in Ess-3 and Ess-4. In both instances, spatial deixis plays an assumptive role as it reflects the authors' assumption that the readers know what the references of the employed spatial deictic terms are. In Ess-3, the first line reads as follows:

(3) I think that the matter raised in that article was... 
The assumption made in (3) is that the readers know that article, and therefore, no further textual clues were given about it. Akin to this usage, Ess-4 uses 'There' as an exophoric device that houses assumptions about the readers' knowledge as shown in (4):

(4) There is the article that appeared in The Guardian devoted to ...

\section{TEMPORAL DEIXIS}

While temporal deictic terms were almost absent from the students' essays - only one such term was used in Ess-3 -, Art-1 and Art-2 employed 10 of these. Quite understandably, the obvious function of temporal deixis was to situate the article's argument within its time context, using expressions like 'this weekend' and 'this week'. Within this general function, Art-2 used temporal deictic references to help the readers draw a timeline of events, since the article was written in a story-like manner and relied on the chronology of events to build its structure. Therefore, Art-2 employed exophoric time expressions like 'After about 15 minutes', 'later in the week', and 'an hour earlier'.

\section{HOMOPHORIC REFERENCE}

As indicated in the instrument of analysis, homophoric reference is analysed in terms of the employment of the definite article in expressions that call for understanding of the cultural background. The total number of occurrences in the six written pieces was nine. Two-thirds of these instances referred to the main topic of debate, which is the burqa. Homophoric reference played a number of roles in the sample essays. Primary among these was to set the scene of the argument by referring to the article's topic in the opening lines as shown in extract (5) taken from Art-1.

(5) He [Ukip leader] set out a new manifesto commitment to ban the face veils worn by Muslim women, such as the burqa and niqab.

A similar attempt was noticed in Ess-1, where the traditional Burqa appears in the opening line. However, instead of employing the homophoric expression to set the scene, it was used to support the argument that banning the burqa would not lead to the expected reduction of security threats. Extracts (6) from Ess-1 and (7) from Ess-3 are a manifestation of this role.

(6) Paul Nuttal forgot that there are more advanced options for hiding a face from CCTV cameras than the traditional Burga.

(7) Nuttal's claim of their need for more security buy banning the burqa is not logical, since people can hide their faces by various means of incognito, e.g. masks.

Taking the same stand, yet in an ironic way, Art-2 also employs homophora to build a logical argument. Consider Example (8) below:

(8) And don't get Ukip started on the burqa. Women in veils were security threats.

In addition to the supportive function, homophora played an assumptive role as it reflected the writers' assumptions about the readers' knowledge of certain expression without further explaining them. Such examples include mentioning 'the Ku Klux Klan' in Art-2 and 'the women's testimony' in Islam in Ess-3. 


\section{CONCLUSIONS AND RECOMMENDATIONS}

Close examination of the literature revealed that homophoric reference was completely absent, while exophoric reference was scantly represented in the studies that investigated the employment of cohesive devices in a variety of texts. As per the findings of this study, exophoric and homophoric devices were found to serve a number of functions in the investigated articles and essays. Exophoric reference served two main purposes, namely supporting the main argument of the article as was noticed in Art-1, Art-2, Ess-1 and Ess-2, and reflecting the assumptions of the authors apropos their readers' knowledge of what certain linguistic items refer to, a role that was evident in Ess-3 and Ess-4. Personal deictic terms were used to serve two functions. The first one was readers' involvement in the argument, which was done through arousing their emotions and via attempting to persuade them using logical argumentation, as was noticed in Art-1 and Ess-1. The second role involved supporting the argument, which was about "self-versus-others" conflicts in Ess-3 and Ess-4. Spatial deictic terms used in Ess-3 and Ess-4 were used to serve an assumptive function similar to that served by exophora in the same two essays. Time deixis was used to set the argument within its time line (Art-2) and time context (Art-1 and Ess-3). As for homophoric reference, it played three roles, supportive, assumptive (two functions played by exophora and spatial deixis) and preparative, to set the ground for the topic of the argument.

The current paper has some recommendations regarding cohesive devices for education and research. Primary among those is the significance of introducing the whole set of devices that can be used to create the text at the levels of form, organisation and meaning. To do so, exophoric and homophoric reference should be at the core of instructional practices that seek to teach writing skills and research practices that seek to analyse discourse. Another recommendation of the current investigation is that more research efforts need to be exerted to further examine exophora and homophora since the literature survey of the present paper has found that these significant tools were not given enough emphasis. One more recommendation can be based on the acknowledgment that the corpus of the present study is not sufficient to generate generalisations. In this regard, since exophora and homophora involve a closed set of linguistic items, research integrating quantitative designs can be conducted to investigate these devices in bigger corpora. While a qualitative enquiry can enrich the knowledge about the functions of exophoric and homophoric reference, quantitative studies can lead to generalisations about certain usages and functions.

\section{REFERENCES}

Abdul Rahman, Z.A.A. (2013). The Use of Cohesive Devices in Descriptive Writing by Omani Student-Teachers. Sage Open. 1-10.

Abu-Ayyash, E.A.S. (2017). Research Practices in Cohesive Devices Studies: Benefiting from Chaos. Theory and Practice in Language Studies. 7(6), 409-418.

Al-Pachachi, A.O. \& Naser, A.A. (2016). The Use of Cohesive Devices in English Drama Texts for Adults and Children. Angloamericanae Journal. 1(1), 28-60.

Awwad, M. (2017). Exophoric and Endophoric Awareness. Arab World English Journal. 8(3), $28-45$.

Bae, J. (2001). Cohesion and Coherence in Children's Written English: Immersion and English-only Classes. Issues in Applied Linguistics. 12(1), 51-88.

Bahaziq, A. (2016). Cohesive Devices in Written Discourse: A Discourse Analysis of a Student's Essay Writing. English Language Teaching. 9(7). 112-119.

Beaugrande, de R. \& Dressler, W. (1981). Introduction to Text Linguistics. London: Longman. Brown, G. \& Yule, G. (1983). Discourse Analysis. Cambridge: Cambridge University Press. 
Celce-Murcia, M. \& Olshtain, E. (2000). Discourse and Context in Language Teaching. Cambridge: Cambridge University Press.

Crossley, S.A., Kyle, K. \& McNamara, D.S. (2016). The Development and Use of Cohesive Devices in L2 Writing and their Relations to Judgments of Essay Quality. Journal of Second Language Writing. 32(1), 1-16.

Cutting, J. (2008). Pragmatics and Discourse. New York: Routledge.

Dedios-Sanguineti, M.C. (2015). Interwoven Explorations: Culture and Mind (in Context). Psychology \& Society. 7(1), 1-11.

Grace, J. (2017). When would Burqa-ban Paul Nuttall Show his Face? Retrieved February 2, 2018 from https://www.theguardian.com/politics/2017/apr/24/ukip-integration-policylaunch-descends-into-full-integrated-fiasco.

Gutwinski, W. (1976). Cohesion in Literary Texts: a Study of some Grammatical and Lexical Features of English Discourse. The Hague: Mouton.

Halliday, M.A.K. \& Hasan, R. (1976). Cohesion in English. London: Longman.

Halliday, M.A.K. \& Matthiessen, M. I. M. (2014). An Introduction to Functional Grammar. London: Edward Arnold.

Hatch, E. (1992). Discourse and Language Education. Cambridge: Cambridge University Press.

Johns, A.M. (1986). Coherence and Academic Writing: Some Definitions and Suggestions for Teaching. TESOL Quarterly. 20(2), 247-265.

Karadeniz, A. (2017). Cohesion and Coherence in Written Texts of Students of Faculty of Education. Journal of Education and Training Studies. 5(2), 93-99.

Liu, M. \& Braine, G. (2005). Cohesive Features in Argumentative Writing Produced by Chinese Undergraduates. System. 33(1), 623-636.

Matsumoto, D. (2007). Culture, Context, and Behavior. Journal of Personality. 75(6), 1285 1320.

Mohamed-Sayidina, A. (2010). Transfer of L1 Cohesive Devices and Transition Words into L2 Academic Texts: The Case of Arab Students. RELC Journal. 41(3), 253-266.

Paltridge, B. (2012). Discourse Analysis. London: Bloomsbury Publishing.

Scott, M. \& Tribble, C. (2006). Textual Patterns: Key Words and Corpus Analysis in Language Education. Philadelphia: John Benjamins.

Smith, R.N. \& Frawley, W. J. (2009). Conjunctive Cohesion in Four English Genres. Text \& Talk. 3(4), 347-374.

Strickland, K. (2017). Paul Nuttall's Burqa Ban Seems to Forget that the Public are more at Risk from White Men than Muslim Women. Retrieved February 3, 2018 from http://www.independent.co.uk/voices/paul-nuttall-ukip-manifesto-burqa-ban-maleviolence-muslim-women-a7698771.html.

Struthers, L., Lapadat, J.C. \& MacMillan, P.D. (2013). Assessing Cohesion in Children's Writing: Development of a Checklist. Assessing Writing. 18(3), 187-201.

Teubert, W. (2010). Meaning, Discourse and Society. Cambridge: Cambridge University Press. Widdowson, H. (2004). Text, Context, Pretext. Malden: Blackwell Publishing.

Yang, W. \& Sun, Y. (2012). The Use of Cohesive Devices in Argumentative Writing by Chinese EFL Learners at Different Proficiency Levels. Linguistics and Education. 23(1), 31-48. 


\section{APPENDIX A}

\section{SAMPLE CODED EXTRACTS}

The ban didn't prevent the devastating Bastille Day Promenade des Anglais truck attack. Nor did the ban make any difference when a man shot a police officer on the Champs Elysees. And if it were in place in the UK it wouldn't have prevented the Westminster bridge terror attack either. (Art-1) ...

The Ukip leader finally broke. "I'm going to speak to the national executive committee later in the week," he said. "The story's about our integration policies today. It isn't about me." (Art-2)

$\cdots$

And don't get Ukip started on the burqa. (Art-2)

Placing a cloth around your neck is considered as a peaceful act while placing it on your nose and mouth is a terroristic one. (Ess-1)

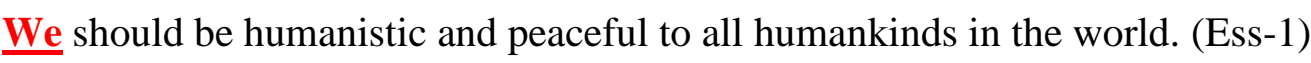

I think that the matter raised in that article was totally against Islam although they claimed that it's not. (Ess-3)

\section{ABOUT THE AUTHOR}

Emad A. S. Abu-Ayyash achieved his Ph.D degree in Education/TESOL from the British University in Dubai in 2016. He currently holds the position of assistant professor in the faculty of education at the British University in Dubai. His research interests include discourse analysis, teaching and learning, translation, assessment and TESOL. 